\title{
Devemos temer a antropofagia? ${ }^{1}$
}

Michel Riaudel $^{2}$

\section{RESUMO:}

O artigo procura ressaltar a polissemia do Manifesto Antropófago, que dialoga dentro e fora do Brasil numa fase de fragmentação do movimento modernista. Por outro lado, embora elaborado sobre a metáfora da antropofagia cultural, que é tudo menos uma forma de sincretismo ou de mestiçagem, o ensaio sugere que o Manifesto institui uma espécie de relação metonímica com o mundo e com o outro.

Palavras-chave: Manifesto Antropófago; primitivismo; metonímia.

\section{ABSTRACT:}

This article seeks to highlight the polysemy of the Cannibal Manifest that dialogue within and outside Brazil in a process of fragmentation of the modernist movement. On the other hand, although elaborated on metaphor of cultural cannibalism, which is anything but a form of syncretism and mestizaje, the text suggests that the manifest establishes a kind of metonymic relationship with the world and with the one other.

Keywords: Cannibal Manifest ; primitivism; metonymy.

1 Comunicação inicialmente apresentada na jornada "Brésil-Europe: repenser le mouvement anthropophagique", organizada pelo Collège international de Philosophie, em 20 e 21 de junho de 2007, na Maison de l'Amérique latine (Paris). Tradução de Silvia Pimenta.

${ }^{2}$ Université de Poitiers, CRLA-Archivos 
A antropofagia foi inicialmente uma pedra de escândalo: a eclosão do manifesto de 1928 e os ventos que sopraram sobre suas produções colaterais: a Revista da primeira dentição, a página semanal no Diário Nacional da segunda... até se converter nas revisões filosóficas pós-1945, na crítica do messianismo cristão, nas teses sobre o matriarcado, na marcha das utopias.

É em maio de 1928 que ocorre, devido sobretudo ao Manifesto, o big bang de onde nasceriam numerosos cometas, planetas, constelações: o concretismo, o tropicalismo, a poesia marginal ou ainda o Teatro Oficina... para falar apenas do Brasil, sem mencionar a repercussão internacional da qual esta jornada é um dos efeitos. E as resistências à Antropofagia de Oswald de Andrade, expressas ao longo deste encontro, são um sinal positivo: sinal de que o Manifesto permanece ativo, escandaloso, apesar do valor de patrimônio que adquiriu desde então. Além disso, como não estamos ainda diante de um texto inerte, é impossível prostrar-nos diante dele numa atitude devota e piedosa, impossível atribuir a ele um sentido definitivo, o sentido. O problema é que, ao mesmo tempo em que resiste à museificação, as múltiplas mensagens atribuídas ao Manifesto não excluem o reducionismo nem os mal-entendidos.

Daí nosso esforço para meter os dentes, desencaixotar seus sentidos, antes de indicar um dos pólos de sua potência subversiva: o trabalho retórico e a visada metonímica.

\section{Os outros "embutidos": a ofensiva}

Aparentemente, a única razão de ser do MA é o outro, a relação com o outro. Mas olhando atentamente, o texto de Oswald de Andrade não mostra um outro com o qual ou contra o qual se defrontar, mas vários outros.

Num primeiro momento, podemos considerar esquematicamente dois outros: o outro do manifesto e o outro da antropofagia. O primeiro é o alvo histórico do texto e tem uma ancoragem, um território: o centro europeu, ou mesmo parisiense, onde se estabelecem então as hierarquias e valores de uma certa literatura do mundo; e é 
também o interlocutor interno, as sucessivas decantações do movimento modernista, de naturezas ideológicas, políticas, religiosas e mesmo estéticas. Este outro é o alvo estratégico do manifesto, contra o qual Oswald dirige seus ataques.

O outro da antropofagia é ao mesmo tempo o antropófago, entendido como outro para o olhar ocidental, em toda sua barbárie explícita, e também os despojos do inimigo que o artista, numa atitude selvagem, se propõe a ingurgitar, engolir. Postulado por princípio, abstratamente e metaforicamente, os contornos deste último são mais difíceis de delinear. Mas é aí que reside o aspecto mais enigmático e fértil do ataque de 1928. Qual a mensagem dirigida aos europeus? Aparentemente, é simples: tratar-se-ia em linhas gerais de reverter as leituras da história, as relações centro/periferia que determinam a escala de valores das literaturas nacionais. Mas, de fato, a análise se revela mais complexa. Um "nós" se afirma, que nesse plano de leitura equivale aos "brasileiros" enquanto prolongamento da figura do Índio, do Tupi. À antiga metrópole portuguesa, o texto envia um novo aviso de independência e de descolonização, reencenando a cena "primitiva" do descobrimento: "Nossa independência ainda não foi proclamada". ${ }^{3}$ Uma vez que a história é sempre escrita pelos vencedores, uma vez que a do Brasil foi confiscada pelos viajantes, missionários e colonizadores, Oswald se encarrega de reescrevê-la, fazendo com que o Brasil dela se reaproprie, no prolongamento dos poemas da seção "História do Brasil" publicados quatro anos antes no livro Pau Brasil. A sátira atinge seu ápice no acontecimento fundador escolhido: o ano da deglutição do "bem nomeado" Sardinha - bem nomeado porque seu patronímico o inscreve temporalmente como português, sua função episcopal o destina espiritualmente ao proselitismo, mas o significante desvia tudo isso em direção ao alimento mais trivial e popular.

O alvo europeu integra também o debate iniciado em 1924 com o Manifesto Pau Brasil, intensificando-o e levando-o além. Já não se trata apenas de mandar as caravelas de volta a seus portos de origem, carregadas de uma poesia de exportação, mas de significar à arte europeia, em plena efervescência primitivista, que essa laboriosa deportação exterior, que exalta os selvagens do Taiti ou as máscaras negras, é realizada sem esforço, espontaneamente, pela natureza brasileira. O poeta brasileiro não precisa imitar, inclinar-se para seu outro (com todos os riscos de paternalismo e de distorções

\footnotetext{
3 “A nossa independência ainda não foi proclamada", Oswald de Andrade, A utopia antropofágica, São Paulo: editora Globo, 1990, p. 52.
} 
que isso comporta), ele é constitutivamente o outro, o selvagem pelo qual a "civilização" europeia está em busca, depois de séculos tentando rebaixá-lo. É nesse sentido que a Revolução Caraíba será "maior que a Revolução Francesa” e que o Brasil é (ou será novamente, se considerarmos as projeções utópicas que absorvem a terra americana) o "país do futuro".

Mas o manifesto visa também o leitor brasileiro, no processo de demarcação que se efetua no seio do movimento modernista a partir de 1922. Os esclarecimentos passam pelos efeitos de clivagem do texto, que o tornam inaceitável pelas vertentes nacionalistas ou espiritualistas do movimento, do verdamarelismo ao grupo de A Anta, etc.

Este não é o momento para esmiuçar os detalhes, mas simplesmente para sublinhar que esse ponto de partida permite reconfigurar as relações com o patrimônio europeu. A relação de concorrência, assinalada anteriormente a respeito da disputa internacional, deixa espaço para uma relação de filiação, no contexto da luta nacional: Villegaignon, Montaigne, Rousseau, Freud, o surrealismo, o bolchevismo..., são invocados para apoiar referências ideológicas destinadas a "combater o inimigo interno”. Daí a ambivalência ou o caráter polimorfo do manifesto e dos signos dos quais ele se apropria.

O ano de 1928 marca também, lembremos, outra ruptura mais obscura: a que ocorre entre as duas grandes figuras do primeiro modernismo, justamente Mário de Andrade e Oswald de Andrade. Se essa ruptura definitiva e não elucidada é objeto de estudos e hipóteses para a história literária, seus desafios podem ultrapassar a investigação historiográfica estrita e contribuir para polarizar escolhas éticas e estéticas. $^{4}$

\footnotetext{
${ }^{4}$ Com relação a essa discussão, remetemos o leitor a dois artigos nossos: "Toupi and not toupi, une aporie de l'être national", in: Mário de Andrade, Macounä̈ma, trad. Jacques Thiériot, édition critique dirigée par Pierre Rivas, Paris : Stock, ALLCA XX, CNRS, 1996. E “'L'anthropophagie, une singularité du modernisme brésilien ? “, in : Rita Olivieri-Godet (dir.), Le Modernisme brésilien, série Travaux et documents, $n^{\circ}$ 10, Saint-Denis: Université Paris 8 Vincennes- Saint-Denis, 2000.
} 
Ao contrapor, por exemplo, a alternativa "Tupi or not tupi" do Manifesto a um hipotético "Tupi and not tupi" de Macunaíma ou da poesia de Mário que associa, precisamente, "o tupi e o alaúde“ 5 , o avesso e o direito da faixa de Moebius.

\section{Os outros " embutidos" (II)}

\section{O outro a priori: questão de princípios}

Para além do contexto de redação do Manifesto, esses outros, dados na história e pela história, ressoam em uma questão mais ampla, a da produção cultural, metaforicamente colocada como impulso de devoração, de assimilação. Seria um equívoco opor esses dois níveis de leitura que coexistem no interior do texto e em suas interpretações .

Mas percebe-se que a apreciação da antropofagia como fato de cultura e como gesto fundador de cultura é mais aberta. Recusemos, entretanto, uma leitura corrente que tende ao clichê e que dilui a antropofagia numa espécie de diferencial brasileiro. A cultura no Brasil, tanto tradicional quanto erudita, seria definida por sua capacidade específica de produzir o novo a partir do velho, de reciclar, absorver, fundir. Esta concepção, em sua generalidade, não significa nada ou significa demais. Não quer dizer nada porque toda cultura é um cadinho, feita de substratos, de empréstimos, de misturas: a tradição não cansa de se reinventar, a criação artística se nutre constantemente daquilo que a precedeu. Nada justifica que se reserve esse processo à cultura brasileira. Além disso, fazer de um universal uma característica nacional dá a entender que haveria em algum lugar, sobretudo na Europa, no Ocidente, culturas puras, imutáveis. Reservar a pulsão canibal à cultura brasileira torna-se suspeito. Significaria que se trata de uma cultura de segunda mão, impura, misturada, degradada, embora interessante? Ou ao contrário, numa postura de valorização, indicaria a associação da devoração à mestiçagem, à ideia de democracia racial, ao sincretismo religioso? Esta última exprime sem dúvida uma melhor intenção, mas conduz ao mesmo resultado: a naturalização da cultura, ou mesmo sua racialização luso-tropical.

\footnotetext{
${ }^{5}$ Cf. o estudo de Gilda de Mello e Souza, O tupi e o alaúde - uma interpretação de Macunaíma, São Paulo : Duas Cidades, 1979.
} 
A compreensão da antropofagia oswaldiana deve, aos nossos olhos, nos levar para outra direção. O próprio escritor delimitou posteriormente as interpretações, especialmente no início da tese elaborada para concorrer a uma vaga de filosofia na Universidade de São Paulo, que acabou não postulando oficialmente. Tratar-se-ia, diz ele em "A crise da filosofia messiânica", escrita vinte e dois anos após o Manifesto, de uma Weltanshauung, de uma comunhão mágico-religiosa que transforma o tabu em totem, própria às sociedades matriarcais. Sem dúvida, algumas afirmações retomam o manifesto de 1928, mas em 1950 elas se integram em um sistema argumentativo muito diferente $^{6}$, tão acadêmico que sua simples forma basta para desmentir o caráter prélógico insistentemente sublinhado pelo Manifesto. Dito de outro modo, as descontinuidades evidentes entre essas duas fases (e a biografia de Oswald nos alerta sobre a frequência dessas rupturas) tornam arriscada uma leitura homogênea de ambos os textos. As diversas reencarnações da antropofagia, pós-modernistas e outras, têm certamente sua legitimidade como desdobramento das potencialidades abertas inicialmente pelo Manifesto. Mas gostaria de retornar ao momento seminal, partindo da ideia de que é essa primeira pedra, fundadora, que constitui o denominador comum deste encontro: só o Manifesto antropófago nos reúne. Podemos também nos voltar com interesse para as interpretações simbólicas fornecidas pelos comentadores dos rituais indígenas, de Montaigne à Antropologia mais recente. Para alguns, a antropofagia seria uma forma de homenagem e de reconhecimento do valor do inimigo, que o canibal faz a honra de comer pelas qualidades que lhe atribui e de que deseja se apropriar. Em resumo, um tipo de eucaristia sem transubstanciação, embora seja através da troca de substâncias, do consumo dos corpos, que a interpenetração dos "espíritos" supostamente se realiza.

Inútil acrescentar que não era esta a percepção dos prisioneiros europeus, a começar por Hans Staden, e por dois motivos: como homem e como protestante. Lembremos aqui a tese de Frank Lestringant de que a Reforma repudia, no catolicismo, uma fantasmática associação com o canibalismo. A antropofagia pode ser, inversamente, concebida como a forma perfeita de vingança, pela qual submeto meu inimigo à humilhação suprema. Eu o "rebaixo" a um alimento, um prato, uma

\footnotetext{
${ }^{6}$ Em "A crise da filosofia messiânica", Oswald de Andrade opõe a antropofagia harmoniosa, que transforma o tabu em totem, ao canibalismo motivado exclusivamente (de forma vil) pela fome e pela gula (Oswald de Andrade, A utopia antropofágica, op. cit., p. 101). Tratar-se-ia de um retorno aos sete pecados capitais?
} 
"sardinha". Para ele faço de meu corpo uma espécie de túmulo, de última morada, ainda que o círculo não termine: o antropófago permanece suscetível de ser, por sua vez, devorado. Simetricamente, a morte de meu inimigo prolonga a minha vida, transformase em lenha que alimenta a combustão de meus órgãos. Em vez de partilhar essa leitura economicista ou de continuar a tomar o fenômeno como signo de barbárie, o célebre estudo de Florestan Fernandes sobre os Tupinambá atribuía à antropofagia uma função social ligada ao papel "religioso" da vingança e da guerra, a seus olhos o motor de integração da comunidade. Manuela L. Carneiro da Cunha e Eduardo Viveiros de Castro - infletem parcialmente essa visão ao fazer da memória da vingança não um fator de transmissão de patrimônio, de laço com o passado, mas de fabricação da identidade com valor teleológico: “ Há uma imortalidade prometida pelo canibalismo [...] trata-se de morrer para haver vingança, e assim futuro. “7

Essas considerações etnológicas nos seriam de pouca valia se não apontassem também em direção a uma retórica da antropofagia, interpretada como afirmação “[...] de um laço metonímico ininterrupto (à moda linhageira) com a ancestralidade. “ ${ }^{8}$ Ora, é precisamente nessa direção que gostaríamos de dirigir nossa leitura: mostrar que o Manifesto de 1928, embora elaborado sobre uma metáfora, a da antropofagia cultural, situa-se retoricamente no campo da metonímia e institui uma espécie de relação metonímica com o mundo e com o outro.

\section{A metonímia, tropo antropofágico?}

No âmbito dos tropos de substituição (e nos restringimos aqui à oposição que atravessa as linhagens de Freud a Lacan e de Jakobson a Genette, sem excluir outras abordagens, como a fascinante noção de metáfora desenvolvida por Jean-François Nordmann) ${ }^{9}$, a analogia tem um estatuto privilegiado, beneficiando-se de toda atenção crítica. Isso resulta sem dúvida do fato de que ela se apoia numa relação com o mundo

\footnotetext{
7 “ Há uma imortalidade prometida pelo canibalismo [...] trata-se de morrer para haver vingança, e assim futuro. “

Manuela L. Carneiro da Cunha e Eduardo Viveiros de Castro, "Vingança e temporalidade: os Tupinambás “, in : Anuário antropológico, n 85, Rio de Janeiro : Tempo brasiliero, 1986, p. 69 et 70.

${ }^{8}$ Ibid., p. 73.

9 Cf. Jean-François Nordmann, "Sur l'expressivité et le pouvoir affectant des métaphores: une perspective phénoménologique", in : Cahiers Philosophiques de Strasbourg, n 3, Strasbourg, 1995.
} 
fundada na correspondência, e portanto num "essencial" implícito que teceria o laço entre aquilo que é comparado e aquilo que serve como base para a comparação. Quintessência da imagem, a metáfora costuma ser interpretada como figura dualista e trinitário, que tende para a essência, para a transcendência, para os além-mundos determinando aproximações possíveis. Nada disso ocorre no caso da metonímia, que não tem passado nem futuro: na ausência de um elemento oculto para transmitir-se de uma instância a outra, a metonímia nunca pode ser desdobrada ${ }^{* *}$, não podemos desenvolvê-la, ela se produz e se extingue no mesmo instante. Ela pertence a um "mundo não datado"10, não tem memória. ${ }^{11}$ Seu tempo é o aiôn, não o chronos. Enquanto acontecimento puro, que consiste em aniquilar e assimilar seu outro, ela tem um caráter performativo particularmente explorado pela escrita de Oswald de Andrade que risca a contradição com um traço da caneta ou a suprime com uma dentada: "Perguntei a um homem o que era o Direito. Ele me respondeu que era a garantia do exercício da possibilidade. Esse homem chamava-se Galli Mathias. Comi-o.” 12 A argumentação torna-se aqui impossível e, aliás, desnecessária. Quando não utiliza a afirmação conclusiva, Oswald recorre à pergunta retórica, que oferece ainda menos margem para a contradição: "Mas que temos nós com isso ?"13.

Aqui, não há comércio ou circulação operando entre dois termos, um dos quais desapareceu. Não estamos mais na era da importação/exportação da poesia pau-brasil, sem falar em " todos os importadores de consciência enlatada " ${ }^{14}$. O "comunismo" dos antropófagos torna vã toda ideia de bem a ser importado ou negociado (trata-se de uma sociedade do otium, não do negotium) ou com o qual especular. ${ }^{15}$ A inexistência da propriedade invalida a própria hipótese de uma dívida a ser contraída e que, além do mais, reintroduziria passado e futuro; interroga a própria ideia de apropriação e de reapropriação. "Contra o Padre Vieira. Autor do nosso primeiro empréstimo, para ganhar comissão." ${ }^{16} \mathrm{O}$ único "intercâmbio", ainda que sem reciprocidade exata, se situa

\footnotetext{
** "Filer une métaphore" significa desenvolver ou desdobrar o tema de uma metáfora ao longo de um enunciado, mantendo como referência a "motivação" original da figura. (N.T.)

${ }^{10}$ Oswald de Andrade, A utopia antropofágica, op. cit., p. 50.

11 "Contra a memória fonte de costume", ibid., p. 51.

${ }^{12}$ Ibid., p. 49.

${ }^{13}$ Ibid., p. 49. E também “Que temos com isso ? “, p. 50. Ou o imperativo "categórico”: "Suprimamos as idéias e as outras paralisias.”, p. 51.

${ }^{14}$ Ibid., p. 48.

15“Não tivemos especulação", p. 50.

${ }^{16}$ Ibid., p. 48.
} 
no nível dos corpos e dos imateriais culturais ${ }^{17}$, não no plano daquilo que equivaleria a uma mercadoria.

Por repousar em uma simples contiguidade, como a que remete o efeito à causa, a metonímia é, a exemplo da antropofagia, um procedimento "pré-lógico"18. Como a escrita paratáxica do manifesto, ela dispensa conectivos - ao contrário da imagem, que não apenas se ajusta a seu uso como faz deles seu próprio critério de declinação: comparação, identificação, metáfora. A única "gramática" ${ }^{19}$ da metonímia é a substituição pura, a expressão necessariamente "in absentia", a desaparição do figurado no figurante.

Apenas isso bastaria para considerar a metonímia o tropo por excelência da antropofagia, a figura da unicidade que subsume o múltiplo: "Da equação eu parte do Cosmos ao axioma Cosmos parte do eu." ${ }^{20}$. O um no um, o outro no um, o devorador e o devorado, o predicado e o sujeito, no fim das contas, são apenas a mesma entidade. Desse ponto de vista, o antropófago seria uma espécie de mônada, sem porta ou janela de fato, não explicitamente engajado na intersubjetividade mas equipado com um tipo de válvula aberta para a diferença: "Só me interessa o que não é meu"21 não postula de modo algum o abandono de si, pelo contrário. A relação do antropófago com o outro consiste quase sempre em uma justaposição negativa ou uma ingurgitação — é assim que podemos entender as dezenove ocorrências da preposição "contra", que funde os valores de oposição e de topologia; no entanto, o antropófago termina por interiorizar a diferença, tornando-se uma espécie de ser "dobrado", um mundo feito de todos os mundos. Ele é o outro e o outro do outro. É por isso que Oswald de Andrade não tem nenhum motivo para citar Picabia, sua revista canibal e numerosas referências europeias escamoteadas, apagadas por deglutição, que nossa leitura do Manifesto pretendeu restabelecer. A antropofagia é um processo de inclusão em que o incluído se torna implícito.

Aliás, "interiorizado" não é o termo adequado, pois a antropofagia não consiste apenas em deglutir, ela se realiza também pelo disfarce. Como a metonímia, ela faz do

\footnotetext{
${ }^{17}$ Oswald de Andrade fala preferencialmente de concreto que de matéria: "Somos concretistas", p.

${ }^{18 \text { "E }}$ a mentalidade pré-lógica para o Sr. Lévy-Bruhl estudar", ibid., p. 48. E ainda "[...] nunca admitimos o nascimento da lógica entre nós.”, p. 48.

${ }^{19}$ “[...] nunca tivemos gramáticas [...]”, ibid., p. 47.

${ }^{20}$ Ibid., p. 49.

${ }^{21}$ Ibid., p. 47.
} 
seu mundo um carnaval de "disfarces", em que o vestuário não é roupa, marcador de civilização, mas fantasia. Em um mundo dualista, que opõe interior e exterior, verdade e aparências, o vestuário é fonte de engano e mentira: "O que atropelava a verdade era a roupa, o impermeável entre o mundo interior e o mundo exterior. A reação contra o homem vestido." ${ }^{22}$. O guarda roupa do antropófago - quando existe - é aberto e permeável, e se vale, ao contrário, da teatralidade do mundo: "O índio vestido de senador do Império. Fingindo de Pitt. Ou figurando nas óperas de Alencar cheio de bons sentimentos portugueses." 23.

Aqui, a máscara é um modo de devoração cujo valor paródico não deve, entretanto, eclipsar seu princípio transcendental: instinto expressivo contra a representação, escansão do eterno retorno. Topologia antes de ser cosmogonia e calendário, a antropofagia se apresenta no fim das contas como uma sintaxe cujos corpos são os significantes: já vimos esse fenômeno no caso do patronímico Sardinha, mas ele já está magnificamente inscrito no célebre "Tupi or not tupi...". Se este é sem dúvida um dos pontos altos desse texto, é porque gera e concentra várias séries. Em vez de analisar todas, gostaríamos de sublinhar a função de repetição, operando duplamente no efeito de citação e no de tradução. Cada uma é uma variante da repetição, exercendo sobre a outra citada ou traduzida (assim como para Hamlet e Shakespeare) seus efeitos de deslocamento (mudança de contexto enunciador) e de disfarce (mudança de código lingüístico). Mas em vez de tomar o referente como elemento estável (passando nesse caso de "to be" a "ser": a essência ou a existência, justamente), é o significante que ancora a repetição, para nos permitir passar de "to be" a "tupi". A letra vence o espírito e trata sem prévia consideração o que as civilizações do tabu sacralizavam com respeito e veneração. A dessacralização antropofágica não implica o desrespeito mas sim uma relação de igual a igual, de totem a totem, onde se abolem as hierarquias. Compreendemos assim que o complexo centro-periferia no qual ainda se inscreve a lógica do manifesto (ainda que para subvertê-la) acaba se dissolvendo na relação antropofágica.

Acrescente-se que o impacto e suas ondas de choque, suas réplicas, devem-se à potência do manifesto, que detém em sua forma e em suas fórmulas uma evidência nada evidente, já que procuramos ainda pensá-la e interpretá-la. O que a antropofagia tem em

\footnotetext{
${ }^{22}$ Ibid., p. 47.

${ }^{23}$ Ibid. p. 49.
} 
comum com Dada é não ser apenas mais um "ismo", mas um ato, uma prática. O manifesto não propõe uma teoria, uma abstração, o que não o impede de se oferecer às análises dos Lévy-Bruhl vindouros, já incluídos. ${ }^{24}$ Dimensão totêmica do texto, da literatura, na medida em que ela não é filosofia e que se debate com o ilegível e com o impensado. $\mathrm{O}$ instinto, na medida em que é linguagem da fisiologia contra a linguagem da moral. ${ }^{25}$ Mais que vingança, o Manifesto é em última instância principalmente ataque, "liberador do ressentimento", no sentido em que Nietzsche opõe os dois termos:

"A minha maneira de ser é guerreira. Atacar faz parte dos meus instintos. Poder ser inimigo, ser inimigo - isso talvez pressuponha uma natureza forte, em todo caso é uma condição de toda natureza forte. Ela precisa de resistências, por isso ela busca resistência: o pathos agressivo faz parte, necessariamente, da força, assim como os sentimentos da vingança e da revanche fazem parte da fraqueza." 26

Em última instância, a antropofagia seria, sobretudo e acima de tudo, um regime, um regime literalmente de com-preensão. Asserções sem demonstração, predicados cujo sujeito foi engolido, frases nominais sem atualização, suas manifestações têm como característica os efeitos de velocidade da elipse, a violência e a ferocidade dramatizada pelo trabalho do negativo, a desarticulação e o desmembramento do catálogo ${ }^{27}$, a energia econômica e pouco fatigante da elisão. A antropofagia não pode ser desdobrada, mas ela se desdobra metonimicamente. Algumas vezes sua virtude deriva mais da prestidigitação do ilusionista que do grande feiticeiro, a despeito das invocações à magia e ao mistério. Ela desdobra sua força retórica na metonímia, mas também na repetição em todas as suas formas: ao mesmo tempo reiteração, evidência do instinto e recurso encantatório. Mas sob a repetição, escrevia Deleuze, é preciso imaginar o precursor sombrio. Sob o júbilo ou a alegria ("prova dos nove" ${ }^{, 28}$ ) da totemização, quem sabe a melancolia do Abaporu. O manifesto antropófago vale por suas latências, que talvez, contra seus outros manifestos, convida a sair da relação alteridade/identidade para introduzir o trabalho da diferença, e mais ainda, da disputa.

\footnotetext{
${ }^{24}$ Ibid., p. 48.

25،[...] é isso que está no princípio dos ensinamentos de Buda - e assim não fala a moral, assim fala a psicologia. [...] trago à luz minha conduta pessoal, minha certeza instintiva na práxis.”, F. Nietzsche, Ecce Homo, I,6. Tradução de Marcelo Backes. Porto Alegre:L\&PM, 2003..

${ }^{26}$ Ibidem

27 “A fixação do progresso por meio de catálogos e aparelhos de televisão.”, ibid., p. 50.

28 “A alegria é a prova dos nove.”, ibid., p. 51.
} 